\title{
MIDAS
}

Museus e estudos interdisciplinares

\section{Félix Dupin-Meynard e Emmanuel Négrier (ed.) - Cultural Policies in Europe: a Participatory Turn}

\section{Flora Maravalhas}

\section{(2) OpenEdition}

\section{Journals}

\section{Edição electrónica}

URL: https://journals.openedition.org/midas/2829

DOI: $10.4000 /$ midas.2829

ISSN: 2182-9543

\section{Editora:}

Alice Semedo, Paulo Simões Rodrigues, Pedro Casaleiro, Raquel Henriques da Silva, Ana Carvalho

\section{Refêrencia eletrónica}

Flora Maravalhas, «Félix Dupin-Meynard e Emmanuel Négrier (ed.) - Cultural Policies in Europe: a Participatory Turn», MIDAS [Online], 13| 2021, posto online no dia 15 dezembro 2021, consultado no dia 05 março 2022. URL: http://journals.openedition.org/midas/2829 ; DOI: https://doi.org/10.4000/ midas.2829

Este documento foi criado de forma automática no dia 5 março 2022.

\section{c) (1) 80}

Midas is licensed under a Creative Commons Attribution-NonCommercial-ShareAlike 3.0 International License 


\title{
Félix Dupin-Meynard e Emmanuel Négrier (ed.) - Cultural Policies in Europe: a Participatory Turn
}

\author{
Flora Maravalhas
}

\section{REFERÊNCIA}

Dupin-Meynard, Félix, e Emmanuel Négrier (ed.). 2020. Cultural Policies in Europe: a Participatory Turn. Toulouse: Éditions de L'attribut e Occitanie en scène. 255 páginas, ISBN 978-2-916002-74-3.

1 Lançado em 2020, Cultural Policies in Europe: a Participatory Turn tem edição de Félix Dupin-Meynard e Emmanuel Négrier, em colaboração com Lluís Bonet, Giada Calvano, Luisella Carnelli e Elettra Zuliani. A publicação foi editada por Éditions de l'Attribut, casa especializada em arte e cultura, fundada em Toulouse, e coeditada pela Occitanie en Scène, uma associação regional para o desenvolvimento das artes performativas da Occitânia.

2 Após a apresentação dos autores, a introdução de Négrier oferece um panorama histórico e teórico sobre o tema da participação no campo da cultura e das artes na Europa. As diferentes conceptualizações de participação, as suas articulações com a política cultural e os respetivos obstáculos de implementação serão retomados e interrelacionadas ao longo dos 11 capítulos que integram o livro.

Os textos aqui reunidos são resultado de um colóquio internacional ocorrido em 2019 em Montpellier, cujos palestrantes são, na sua maioria, os autores desta obra. 0 livro gira em torno de três questões: «Por meio de que processos se está hoje a desenvolver na Europa a participação na arte e na cultura? A que contrastes dá origem a participação, em termos de intensidade, modelos e culturas nacionais ou sectoriais? Como é que essa participação coloca as questões culturais no centro dos dilemas democráticos do século XXI?» (p. 25, tradução da autora). 
4 Este livro está dividido em duas secções. Na primeira, «What Participatory Turn? Participation Dynamics and Policies», os cinco capítulos que a compõem interrelacionam teorias e métodos de participação com história e política nos territórios nacionais europeus. Na segunda, «Participation and Cultural Policy Challenges», os seis capítulos relacionam a política cultural com temas de participação relativos a outros âmbitos de política pública.

50 objetivo do primeiro capítulo, «Participation(s) Typologies, Uses and Perceptions in the European Landscape of Cultural Policies», é contribuir para o tema de como a participação é promovida, incluída e implementada nas políticas culturais europeias. Para a difícil tarefa de traçar uma cartografia europeia, Dupin-Meynard e Villaroya iniciam aclarando termos e tipologias relativos ao tema da participação cultural nos diferentes territórios. A partir desse ponto, explicam os diferentes métodos empregados na realização da pesquisa apresentada, que contou com a condução de um questionário aplicado a especialistas em políticas culturais de 12 países.

6 Em «Between Cultural Participation, Trust and Policy Perspectives: The Case of the Creative Europe Program», Giuliana Ciancio examina como a União Europeia redefiniu, a partir da participação, o propósito de sua ação cultural como resposta a uma sociedade que passa por uma crise de confiança entre cidadãos e representantes políticos. Numa tentativa de compreender como a cooperação cultural e a participação europeia têm auxiliado na renovação da noção do espaço europeu, são analisados os programas "Creative Europe" e "Be SpectACTive".

7 O ponto de partida do capítulo de Lluís Bonet e de Mariano Martín-Zamorano é a relação entre democracia e participação. Embora estas duas tendam a caminhar juntas, a participação pode ser cooptada por regimes autoritários ou iliberais. Em «Citizen Participation in Liberal and Illiberal European Cultural Policies», os autores distinguem contexto cultural, modelo de governança e estratégias culturais, e discutem as diferenças entre participação cidadã, desenvolvimento de públicos e estratégias de participação cultural nos contextos das democracias liberais e iliberais. A política cultural, no âmbito iliberal, foca o seu discurso em identidade, orgulho nacional e interesses populistas. Desse modo, as ações que não estejam ao serviço da exaltação do projeto ideológico são marginalizadas e, por vezes, perseguidas.

8 A partir das seis edições de L'Enquête Pratiques Culturelles realizadas entre os anos de 1973 e 2018, Loup Wolff fornece uma análise das práticas e dos comportamentos dos habitantes da França em «Participation in Cultural Practices: Which Statistical Trends?». Na última edição da pesquisa, também foi aplicada a técnica de análise de correspondências múltiplas. Os dados apresentados indicam que houve aumento e diversificação da presença da cultura como parte da vida quotidiana, resultados dos efeitos graduais e modestos das políticas culturais. No entanto, as práticas culturais em França permanecem ainda condicionadas a dinâmicas geracionais e a um certo peso social. O autor conclui que, apesar das tecnologias digitais, não houve incremento na participação social, de modo que promover a participação não pode apenas basear-se em ferramentas digitais para transformar as práticas. Ao fazer isso, na verdade, há um risco de se agravarem as desigualdades de acesso.

Na entrevista «What's New About Participation?», são feitas três perguntas aos especialistas Franco Bianchini, Luca Dal Pozzolo, Jean-Damien Collin e François Matarasso. São abordados temas como: o conceito de participação na história da arte e o seu papel na política cultural; as diferentes matrizes do conceito de participação e as 
respetivas influências na definição das políticas culturais; além do efeito da atual crise sanitária nas organizações culturais que têm a participação como tema central de atuação.

10 A segunda parte da publicação, «Participation and Cultural Policy Challenges», articula a temática da política cultural com outras questões de política pública, visto que a participação não é mera função das políticas culturais. De acordo com Négrier, as fronteiras das políticas culturais são constantemente ultrapassadas, e são «essas interações materiais e simbólicas que estão entre os objetos mais emocionantes (de estudo e ação)» (p. 26, tradução da autora).

11 Dessa forma, a interação entre território/planeamento urbano e políticas culturais é o tópico de «Cultural Participation and Territorial Development: Some Insights from the Portuguese Case». Pedro Costa observa que nas últimas décadas se verifica um inquestionável aumento da dinâmica participativa em Portugal, tanto no sector público como na ação de agentes e instituições culturais. São alguns os exemplos expostos, entre os quais: o projeto "Bairros Críticos", que testa novas formas de governanças em bairros desprivilegiados; o "Artemrede", uma rede de municípios de apoio à criação artística; e o programa "PARTIS", da Fundação Calouste Gulbenkian, que visa apoiar projetos cuja metodologia central seja a prática artística ao serviço do campo social.

12 Com Hanka Otte e Pascal Gielen, a interceção é entre participação e bens comuns culturais. O capítulo «Commoning Art as Political Companion. On the Issue of Participatory Democracy» indaga se a democracia participativa não é uma tautologia, da mesma forma como commoning politics também não seria. Destaca-se o conceito de política cultural agonística, inspirada em Mouffe (2013), que seria a forma de pôr em prática uma democracia ativa, não limitada ao debate no espaço público ou cívico, por meio da arte e da cultura. "Montaña Verde", "The Tower of Babel" e "The Ground of Things" são três casos em que artistas e organizações culturais propuseram a utilização de um recurso comum - praça pública, língua e terreno público, respetivamente - como tentativa de alterar essa gestão de recursos comuns para uma estrutura a partir de princípios de commoning.

13 Em «What Music Worlds do to Participation. A Cross-Sectoral Perspective», o tema da participação artística é articulado com o domínio da world music, que culmina no ano 2000 como um nexo de estratégias intersectoriais, em que política urbana, desenvolvimento territorial e políticas socioeconómicas se conectam. Sandrine Teixido relaciona os temas da participação com a música e faz um breve historial da ligação da música com políticas setoriais, para então apresentar três exemplos de festivais de world music: "Mandinka Christmas", "États Généraux des Musiques du Monde" e "Mulhouse Capitale du Monde".

14 Em razão da pandemia covid-19, Niels Righolt escreve o seu texto a partir de um novo local de trabalho. «Perspectives from a Kitchen Table. The Re-discovery of Cultural Democracy Post the Coronavirus - Crisis as Opportunity and Value» aborda a questão das ligações entre a participação, no sentido cívico do termo, e a participação artística e cultural, particularmente no que diz respeito à Dinamarca, além de imaginar cenários num mundo pós-pandemia.

15 Carnelli e Zuliani refletem sobre a transferência para a Internet de atividades culturais geralmente associadas à presença física em «The Turn of the Screw of the Digital: From an Exceptional Time, to a New Temporary Reality». A saturação de conteúdos digitais demandou artistas e organizações culturais a criarem novas linguagens e formas de 
comunicação aptas a conectar um mundo em distanciamento social. As autoras apresentam algumas ações culturais que fugiram dos modelos tradicionais, tais como a utilização de ligações por telefone, áudios gravados e enviados por WhatsApp, seleção e envio de títulos literários por livreiros especializados, residências artísticas digitais e o caso específico da companhia de teatro Nesterval, que optou por estrear uma peça em que todos os participantes - público e atores - estavam conectados por zoom. A pandemia covid-19 oferece diversas perspetivas de futuro e é possível aproveitar essa mudança digital para conectar diferentes públicos e dar acesso a mais participantes.

A segunda entrevista, «Participation and Intercultural Challenges», é realizada a Milena DragićevićŠešić, que relata experiências de participação na Europa periférica, como os comitês do século XIX denominados Matica, cuja finalidade era desenhar e implementar as suas próprias políticas culturais. A autora reforça a necessidade de a Europa orientar as suas políticas culturais para a interculturalidade e para os direitos culturais, visto que, apesar de ser um ambiente intercultural, representa ainda uma voz homogénea. Como avanço, referencia as conquistas da população Sámi na Finlândia e na Suécia em obter alguns direitos para decidir sobre o seu próprio desenvolvimento. Por outro lado, cita a quase total ausência (e até rejeição) da presença da cultura da comunidade Roma dentro do sistema público de cultura europeu. Sobre as práticas participativas de política cultural, reforça a necessidade de abertura a uma pluralidade de níveis de intervenção, sendo crucial o nível local para a participação dos cidadãos. Em contraponto, atenta ao facto de que a democracia direta também pode dar espaço a exemplos negativos de práticas participativas, como aquelas que acabam por enfatizar valores neoliberais, como a competitividade.

A temática que serve de eixo à publicação é ampla, ainda assim, os capítulos que a compõem são capazes de abordar o tema da participação a partir de diferentes perspetivas teóricas e históricas, além de oferecer reflexões políticas e exemplos de práticas participativas da área da cultura em diferentes espaços geográficos europeus.

o livro em recensão constitui-se como uma relevante contribuição para que se pense nas nuances que o tema da participação pode ter no âmbito das políticas culturais. E termina exatamente como começa, propondo uma reflexão a partir de perguntas que giram em torno de três temáticas: «os valores políticos e democráticos de participação (...); os usos da participação como resposta a desafios sociais, territoriais e interculturais (...); e a participação à luz da pandemia covid-19» (p. 217, tradução da autora).

\section{AUTORES}

\section{FLORA MARAVALHAS}

Instituto Superior de Ciências Sociais e Políticas da Universidade de Lisboa, Portugal, flopitz@gmail.com 